\section{Criminalization of drugs}

SIR-Your leading article "Bush declares war on drugs" (Nature 341, 1; 1989) is right in noting that if drug-related crime is to be totally eliminated, all drugs would have to be decriminalized, but it must be hoped that neither the United States, nor any other country for that matter, ends up decriminalizing narcotics or illicit drug use altogether.

You ask "would not a society in which narcotics were accessible that did not destroy itself by addiction be a stronger society and perhaps even kinder and gentler as well?". Problem drug-users have frequently told me, in the ten years in which I have worked with them, that "heroin blanks you out, it makes you emotionally distant". Many other drugs have even nastier and more antisocial effects. In the affluent West, the desire to achieve self-realization is common. Unfortunately, because of large-scale pharmaceutical drug use, it has become a drug-focused society. To be realistic, heroin and other euphoric and mindaltering drugs, whose use can at first be pleasurable, would be used on a wide scale if they were easily accessible. Would we want large sections of the population wandering around emotionally isolated and cut off from meaningful relations with others? Such a society would hardly be "kinder or gentler".

Clearly some degree of criminalization is necessary. But what is needed is a sensible policy suited to the real needs of containing the drug problem. For example, heroin, cocaine and crack are this decade's fashion. Designer drugs will be the major threat in the future. Should there not be international laws outlawing and controlling the illicit manufacturing of all synthetic drugs before they become a fashion?

Further, the British did not, as the author claimed, give up prescribing narcotics some 20 years ago because of the over-prescribing of one doctor. Rather, in the 15 years after the drug dependency clinics were set up in 1968, their consultant psychiatrist directors generally found that such long-term prescribing was medically harmful. Also, it generally did not help addicts to lead normal lives or keep them from crime. Even so, a small number of doctors continued to maintain addicts. Recently, in a move to combat AIDS, their numbers have increased. Most, however, offer only short-term treatment with reducing doses and aim to wean their patients off drugs as soon as possible.

Liberal prescribers such as Trebach argue that the British system of treatment was the reason why, until the $1970 \mathrm{~s}$, Britain had only a small drug problem. But, as I have indicated elsewhere, it was precisely because numbers were small that such a policy could be pursued. When the size of the addict population rapidly escalated in the $1980 \mathrm{~s}$, treatment and prescribing policies were ineffective in controlling the size of the addict population because heroin was cheap and easily available on the street. While illicit drugs remain easily available on the street, many of the addict population will, for a number of reasons, prefer not to seek maintenance prescriptions, but seek to buy illicitly - if for example, they are only recreational users, or they hate authority and the restrictions imposed by drug dependency units or prefer the excitement of the illegal subculture. And the drug market is organized in so complex a way that it would stimulate a demand on the street for their pharmaceutical drugs. Instead, large-scale liberal prescribing would increase the size of the illicit market, for it would lead to an extensive pharmaceutical blackmarket fed from the overspill from liberal prescribing.

It would be a very foolish policy-maker indeed nowadays who confused 'treatment' with drug control policy or containment.

Department of Sociology, National University of Singapore, 10 Kent Ridge Crescent, Singapore 0511

\section{Collision course}

SIR-The race between the Stanford Linear Collider and the Large ElectronPositron Collider at CERN, the highenergy physics laboratory near Geneva, to be the first to elucidate the properties of the $Z^{0}$ particle raises fundamental questions about the purpose of particular scientific research projects in an era of increasing costs and declining resources. It was known from the beginning that the CERN machine would be able to produce $Z^{0} \mathrm{~s}$ in much larger numbers than the Stanford machine. Thus, there was never an expectation that Stanford could produce data that would not eventually be available from CERN. The only question was whether Stanford could produce some of these data first. If some properties of the $\mathrm{Z}^{0}$ had become known a few months earlier because of the Stanford experiment, it would have had absolutely no effect on scientific progress. It would, however, have been of significant advantage to the careers and reputations of the scientists involved in the Stanford experiment.

When the cost of a single machine such as the Superconducting Super Collider can approach the gross national product of a small developing country, we should question whether the taxpayers should be continuously called upon to support this kind of pointless competition and duplication of effort. If CERN, the United
States, the Soviet Union and Japan cannot get together to fund and build a single high-energy physics machine, we should at least try to ensure that expensive facilities in one country complement rather than duplicate the capabilities of machines available elsewhere.

ROBERT J. YAES

Department of Radiation Medicine, University of Kentucky,

Lexington, Kentucky 40536-0084, USA

\section{Stanford scandal}

SIR-Dr Donald Kennedy (Nature 341, $180 ; 1989)$ was not president of Stanford University at the time of the assault on Professor Leonard Hayflick, to which I alluded in a review - he was, I believe, head of the Food and Drug Administration in Washington - but the affair caused an international scandal, and unawareness among faculty members, even those who were not physically present, implies the lack of academic solidarity of which I complained.

I think that if Kennedy reviews the history of this affair, he will find my comments neither unjust nor intemperate.

The Windmill House, The Hill,

ALEX COMFORT

Cranbrook, Kent TN17 3AH, UK

\section{Six of one ....}

SIR-Although one instinctively feels that all information is of value, the data quoted in your recent News and Views comment (Nature 341, 181; 1989) on the British National Survey of Sexual Attitudes and Lifestyles suggest that Mrs Thatcher was right to doubt its value.

You quote the results of a preliminary survey as showing the average (lifetime) number of heterosexual partners as 11.0 for men and 2.9 for women. These figures are literally impossible. A heterosexual union is analagous to a heteronuclear chemical bond, and the total number must be the same if viewed from the male or female end. Thus the average numbers of partners must obey a 'bond consistency' condition

$$
c_{\mathrm{M}} N_{\mathrm{MF}}=c_{\mathrm{F}} N_{\mathrm{FM}}
$$

where $c$ is a concentration and $N_{\mathrm{MF}}$ the number of female partners per male. Because by empirical observation the concentrations of males and females in the United Kingdom are the same, so must the average number of partners be. The survey results are clearly biased: probably both sexes bias their replies ("lie") in socially acceptable directions. The sociologist you quote was clearly right to be sceptical.

\section{Department of Physics,}

University of Leicester, Leicester Road,

Leicester LE1 7RH, UK 